\title{
0 que [não] dizem as entrelinhas: Análise dos casos de abandono de uma clínica-escola em psicologia
}

\author{
Isabela Cedro Farias \\ Samara Vasconcelos Alves \\ Camilla Araújo Lopes Vieira
}

\section{RESUMO}

Estudos sobre clínicas-escola de psicologia constatam elevados índices de desistência/abandono nos atendimentos individuais. Diante dessa informação, este artigo trata da análise dos encaminhamentos feitos da atenção básica da saúde a uma clínica-escola de psicologia de uma instituição de ensino superior. Nosso objetivo é aprofundar o entendimento, nesse contexto específico, das causas que levam ao abandono e também explorar a diferença existente entre conveniência e resistência ao tratamento. Foi realizada uma pesquisa mista, de caráter quanti-qualitativo e documental. 0 corpus foi composto por 133 prontuários, do período de 2014 a 2016, de usuários que interromperam o tratamento. Os dados foram analisados à luz da Análise de Discurso Crítica (ADC) através das categorias analíticas interdiscursividade e intertextualidade. Os resultados mostraram que variáveis relacionadas a problemáticas sociais tem um peso tão significativo quanto o desejo dos pacientes de permanecerem em atendimento. 0 estudo também revelou que os motivos que levam ao abandono são diversos e singulares. A expectativa dos pacientes de um tratamento que esteja em conformidade com o modelo biomédico e farmacológico, por exemplo, foi um fator de abandono. A pesquisa concluiu que as clínicas-escola são espaços que sobrevivem e resistem no trabalho de acolhida dos sujeitos em sofrimento.

Palavras-chave: Psicoterapia; Clínicas-escola; Desistência do tratamento; Resistência.

\section{ABSTRACT \\ What the between the lines [doesn't] say: Case analysis for abandonment in a psychology clinical school}

Studies about school clinics in psychology have shown that withdrawal/defaulting happens with a high frequency in individual care. In the face of this evidence, it was analyzed the referrals made by the primary health care to a clinical school in psychology from a higher education institute. One of the goals was to further the understanding, on this specific context, of the causes for defaulting. Also, it was explored the differences existent between convenience and resistance to the treatment. The study was developed using mixed and documental research. The corpus was made by 133 patient records that, from 2014 to 2016, had interrupted the treatment. The data about the situation was analyzed with the Critical Discourse Analysis (ADC) through the intertextuality and interdiscursive analytical categories. The expectations from the patients for a treatment that was in accordance with the biomedical and pharmacological models, for example, was a factor for defaulting. The study has also revealed that the reasons that make the patients stay or leave are diverse and singular. In the end, it was concluded that school clinics are spaces that survive and resist working with the welcoming of the subject is suffering.

Keywords: Psychotherapy; School-clinics; Treatment dropouts; Resistance.

\section{Sobre os autores \\ I. C. F. \\ http://orcid.org/0000-0002- \\ 5258-0946 \\ Universidade Federal do Ceará - \\ Sobral, CE \\ behlafarias@hotmail.com}

\section{S. V. A.}

http://orcid.org/0000-0002-

5452-2336

Universidade Federal do Ceará Sobral, CE

alves.sv@gmail.com

\section{A. L. V.}

http://orcid org/0000-0003-

1706-3772

Universidade Federal do Ceará Sobral, CE

tgd.camilla@gmail.com

\section{Direitos Autorais}

Este é um artigo de acesso aberto e pode ser reproduzido livremente, distribuído, transmitido ou modificado, por qualquer pessoa desde que usado sem fins comerciais. 0 trabalho é disponibilizado sob a licença Creative Commons CC-BY-NC.

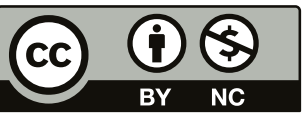


A clínica-escola em Psicologia se configura como sendo um ambiente associado a uma instituição de ensino, no qual o aluno completa sua formação ao realizar a prática clínica, sob a orientação de um professor supervisor (Gauy \& Fernandes, 2008). Sua implantação é prevista pelo parecer $403 / 62$ que criou a profissão do psicólogo e pela lei 4.119/62, que regulamenta a existência de serviços clínicos abertos ao público, gratuitos ou remunerados, dirigidos por conselhos dos professores de cursos superiores em psicologia, cujo objetivo é articular a formação educacional com o exercício da profissão.

Na realização de uma pesquisa, que objetivava analisar os encaminhamentos realizados da atenção primária à saúde a uma clínica-escola de psicologia de um município de grande porte do nordeste brasileiro, percebemos a necessidade de também fazermos, de maneira anterior à pesquisa, uma revisão de literatura sobre estudos que abordassem a temática das clínicas-escola de psicologia. Embora não fosse especificamente nosso objetivo, não nos passou despercebido que diversos estudos verificaram a existência de um elevado índice de desistência/abandono nos atendimentos individuais (Ancona Lopes, 1983; Campezatto \& Nunes,2007; Jung, Serralta, Nunes \& Eizirik, 2014; Maravieski \& Serralta, 2011; Sei \& Colavim, 2016). Alguns deles sustentam que a quantidade de abandonos representa quase a metade do público que procurou o serviço (Lhullier, Nunes \& Horta, 2006).

Esse indicativo foi interpretado como uma sinalização para que as clínicas-escola avaliassem seus serviços e repensassem algumas formas de atendimento, sobretudo a psicoterapia individual. Essa é uma visão compartilhada por muitos dos autores, inclusive, segundo a qual a formação em psicologia deveria se adequar aos novos tempos e novas demandas sociais (Justen et al., 2010), que os psicólogos deveriam se ajustar à nova realidade brasileira (Sassi \& Maggi, 2007), fazendo uma crítica ao currículo dos cursos de Psicologia, cuja ênfase é entendida como demasiadamente clínica (Prebianchi $\&$ Cury, 2005). Diante desse contexto, alguns autores propõem que os grupos deveriam ser uma técnica mais utilizada nas clínicas-escola e que ações como assessorias a escolas, promoção de saúde na comunidade e grupos de sala de espera (Justen et al., 2010) também deveriam ser realizadas.

Mantovani, Marturano e Silvares (2010) afirmam, contudo, que antes de enveredar por essa crítica é importante entender o que se caracteriza como abandono e o que é desistência. Alertam que os estudos não são facilmente comparáveis entre si em função do uso de métodos diferentes e da adoção de diferentes entendimentos do que constitui o abandono. Assim, defendem a ideia de que desistência é a renúncia ao tratamento antes mesmo dele começar e abandono é a interrupção do tratamento já iniciado. Nesse sentido, o foco deste estudo é as situações de abandono, ou seja, interrupção do tratamento já iniciado. Os motivos do abandono são apresen- tados como sendo relacionados com a linguagem tecnicista do psicólogo (Cunha \& Benetti, 2009), com a falta de diálogo com os pais (no caso de atendimento de crianças) e devido à localização do serviço (Prebianchi, 2011). Bados, Balaguer e Saldanã (2007) constataram que os motivos que mais levaram ao abandono de tratamento em uma clínica-escola da Universidade de Barcelona foram: a insatisfação com o tratamento ou terapeuta $(46,7 \%)$, dificuldades não relacionadas ao tratamento ou à instituição (40\%) e a ausência de percepção de melhora em seu sintoma (13,3\%).

O mais contraditório é que se de um lado há um grande número de abandono, de outro temos longas filas de espera e consequentemente um extenso período para o início do atendimento (Sei \& Colavim, 2016). Diante desse cenário, e dentro de um recorte menor da pesquisa que estava sendo executada, nos interessamos por explorar um pouco mais sobre a situação do tratamento dos casos encaminhados à clínica-escola em estudo. Perguntamos se de fato o abandono era algo que acontecia com frequência. Quais os motivos que estavam por trás da não continuidade do acompanhamento psicológico? O que é conveniência e o que é resistência ao tratamento? A confirmação desse fenômeno justificaria a substituição do atendimento individual por procedimentos alternativos, como atividades em grupo?

Adiante apresentaremos de que forma conduzimos a pesquisa e quais foram seus principais achados.

\section{MÉTODO}

\section{TIPO DE PESQUISA E LOCUS}

Este estudo faz parte de uma pesquisa maior intitulada Análise dos encaminhamentos realizados da Atenção Primária à Saúde (APS) de Sobral-Ce ao serviço de psicologia aplicada do curso de Psicologia da Universidade Federal do Ceará . A pesquisa foi quanti-qualitativa e documental, partindo de uma pergunta exploratória. Giddens (1991) considera que a pesquisa pode ser feita pelo método misto quantitativo e qualitativo quando se pretende obter uma compreensão e explicação mais ampla do tema estudado. A pesquisa foi realizada no Serviço de Psicologia Aplicada (SPA) Raimundo Medeiro de Frota [informação suprimida para não identificar o(s) autor(es)], do curso de Psicologia da Universidade Federal do Ceará , localizado no centro da cidade de Sobral-Ce [informação suprimida para não identificar o(s) autor(es)]. No município, o curso de Psicologia existe desde 2006 e tem o SPA como um dispositivo que completa a formação do aluno, ao mesmo tempo que promove o contato com a comunidade. Entre as atividades realizadas no SPA tem-se: acolhimento, triagem, atendimentos individuais, atividades grupais, entre outros. Cabe mencionarmos que a cidade de Sobral tem relevância no cenário da Saúde Pública em nível nacional por ser 
referência do modelo tecnoassistencial da rede de saúde, com especial destaque para a Rede de Saúde Mental.

Na clínica-escola, após passarem pelo acolhimento e pela triagem, os pacientes ficam esperando o contato do serviço para o início dos atendimentos individuais semanais. A nossa análise tomou como referência esses casos: pacientes que já haviam iniciado seu processo terapêutico e que por algum motivo abandonaram.

\section{AMOSTRAGEM E COLETA DE DADOS}

Quanto ao procedimento, trata-se de uma pesquisa documental, uma vez que os prontuários do SPA serviram de base para a coleta de dados. Tais prontuários passaram por uma categorização de informações: data de admissão, sexo, idade, queixa, forma de encaminhamento, procedimento adotado e situação atual. Este estudo trata especificamente desse último aspecto.

A amostra da pesquisa foi construída por 133 prontuários. Chegamos a esses prontuários a partir de dois processos. Inicialmente foram estudados os mil primeiros prontuários de atendimentos realizados do serviço, que iniciou sua atividade no ano de 2014. O recorte do período foi, então, entre 2014 a 2016. Os dados coletados foram analisados a partir do programa IBM Statistical Package for the Social Sciences for Windows (SPSS). Tal processo nos levou especificamente às informações sobre os encaminhamentos ao SPA pela APS do município. Foram 293 o total de prontuários que vinham encaminhados da atenção básica de saúde. Destes, 133 casos abandonaram o tratamento, sendo o recorte de estudo que utilizamos nesse estudo específico. A coleta de dados foi realizada entre os meses de abril a julho de 2016 na sala de arquivo dos prontuários do SPA.

\section{ANÁLISE DOS DADOS: ANÁLISE DE DISCURSO CRÍTICA}

Utilizamos como método de análise de dados a Análise de Discurso Crítica - ADC. Segundo Resende e Ramalho (2011), esta consiste em "um conjunto de abordagens científicas interdisciplinares para estudos críticos da linguagem como prática social" (p. 12). Baseado no entendimento do discurso como prática social e, mais do que isso, como produtor de sentidos que atuam a serviço de projetos particulares de dominação e exploração, optamos pelo uso de tal método, uma vez que realizamos reflexão crítica dos materiais de que dispomos.

Ainda como forma de tornar a discussão mais rica e representativa, utilizamos trechos de alguns registros dos prontuários analisados. Para manter o sigilo do usuário do serviço, o prontuário foi representado pela letra $P$ seguido do número referente à ordem do prontuário (Ex.: P123, referente ao $123^{\circ}$ prontuário na ordem dos registros).
Para que possa ser melhor compreendido, se faz necessário que exploremos alguns pontos importantes da ADC, como discurso. $O$ entendimento sobre o discurso é uma pedra basilar dentro da abordagem. Dentro da concepção tridimensional do discurso, Fairclough (2001) considera os três eixos: texto, prática discursiva e prática social. 0 texto representa o sistema linguístico propriamente dito, a prática discursiva é o momento da linguagem como texto em contexto e as práticas sociais são "[...] maneiras recorrentes, situadas temporal e espacialmente, pelas quais pessoas interagem no mundo." (Resende \& RamaIho, 2011, p. 43). Trazendo a teoria tridimensional para o nosso estudo, podemos entender a nossa análise como envolvendo o texto (prontuários) que apresentam práticas discursivas importantes (discurso biomédico) e que podem se materializar em uma prática social específica (abandono).

Ainda na Prática Social, temos um processo com relações dialéticas de três momentos internos: Gêneros, Discursos e Estilos. Gênero está relacionado com o tipo de linguagem ligado a uma atividade social. Discurso está ligado a aspecto da realidade, articulado a maneiras particulares de representar o mundo. O Estilo é um tipo usado por uma categoria particular de pessoas e em relação com sua identidade, fazendo analogias com as maneiras de identificar-se. $\mathrm{Na}$ ordem do Gênero, utilizamos a categoria analítica Intertextualidade (propriedade que têm os textos de serem cheios de fragmentos de outros textos). Na ordem do Discurso, elencamos a Interdiscursividade (heterogeneidade dos textos em termos de articulação de diferentes discursos) como outra categoria selecionada para a análise.

\section{PROCEDIMENTOS ÉTICOS}

Os prontuários que foram analisados são fontes sigilosas de informações. Têm acesso ao seu manuseio apenas os estagiários, coordenadores do serviço e professores-supervisores. Diante desse fato, inicialmente enviamos o projeto de pesquisa para a apreciação do colegiado do curso de Psicologia e só com a aprovação dele foi que se deu continuidade ao processo de cadastro do projeto de pesquisa. Submetemos a presente pesquisa ao Comitê de Ética da Universidade Federal do Ceará, através do portal eletrônico da Plataforma Brasil. $O$ projeto foi aprovado nos termos do parecer $n^{\circ} 1.520 .402$ e CAAE: 53570816.1.0000.5054.

\section{RESULTADOS E DISCUSSÃO}

Como já mencionado, na literatura revisada sobre clínicas-escola de Psicologia, a modalidade de atendimento individual era por vezes questionada pelas altas taxas de abandono. Especificamente na nossa pesquisa, observamos a situação do tratamento dos prontuários compreendidos entre 2014 a 
2016. Dentre os 293 prontuários estudados, 96 casos passaram exclusivamente pela triagem, 32 estavam em espera e 28 tiveram um mês de tratamento. Os demais casos podem ser acompanhados na Figura 1, sendo o total de 133 casos de abandono no período estudado.
(Prebianchi, 2011). Como motivo para não aderência ao tratamento, apareceu a dificuldade de transporte para quem mora em algum distrito ou localidade distante da sede do município, e até mesmo para os que moram na sede. Como já citado, o SPA funciona no centro da cidade, ficando de fato distante

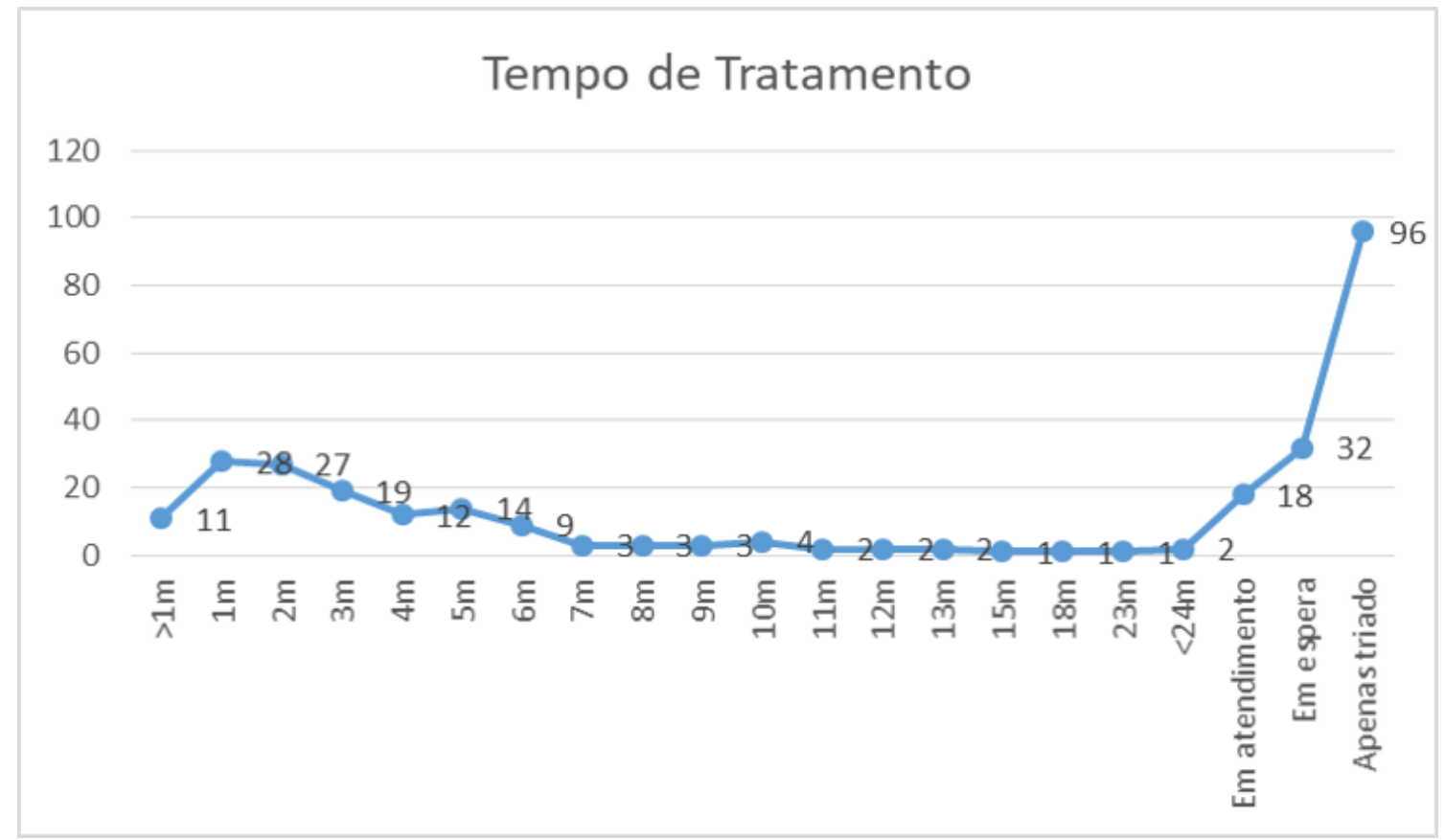

Figura 1. Situação do tratamento dos casos encaminhados da APS.

Mesmo assim, 18 dos casos encaminhados via APS ainda estão em atendimento. Ainda em relação a tais dados, podemos concluir que quase metade dos casos estão, de certa forma, em espera. Isto é, aos 32 casos citados que aguardam o início dos atendimentos, poderíamos somar 96 que só passaram pela triagem. A informação de que 28 só tiveram um mês de tratamento está em consonância com o que foi problematizado por Jung e seus colaboradores (2014) que constataram que as taxas de abandono sempre são mais elevadas no primeiro mês.

Antes de tirarmos a conclusão (que avaliamos como simplista) de que os abandonos são frequentes nos casos atendidos no SPA, encaminhados pela APS, cabe detalharmos algumas particularidades da realização dos atendimentos no contexto do serviço estudado. Encontramos como motivos para abandono situações bem diferentes e mais variáveis do que as apontadas pela literatura, a saber: a linguagem tecnicista do psicólogo (Cunha \& Benetti, 2009), a falta de diálogo com os pais (no caso de atendimento de crianças) e as dificuldades quanto ao acesso e à localização do serviço de alguns bairros. Por questão de proximidade, muitos alegavam estar tentando ser atendido no próprio Centro de Saúde da Família (CSF) da sua comunidade, por ser mais conveniente. Adiante ampliaremos a discussão sobre a diferença entre conveniência e resistência ao tratamento.

Identificamos, mais detalhadamente, uma gama de outros motivos, como a questão do horário. Como o SPA funciona no expediente comercial, muitos pacientes abandonavam os atendimentos tão logo conseguiam um trabalho. No caso de quem trabalhava, não continuava a ir às sessões por não terem a permissão em seus empregos de ficarem disponíveis para o atendimento no horário que o serviço dispunha. Isso acontecia inclusive no atendimento das crianças, já que elas dependiam do horário livre dos pais ou responsáveis para irem ao SPA. Em outros casos, o paciente solicitava mudar o horário de atendimento, mas não havia compatibilidade com a agenda de nenhum estagiário. Durante o primeiro ano de atendimento do serviço, em 2012, ocorreu uma greve dos professores da Universidade com a duração de quatro meses. Em consequência, o SPA Raimundo Medeiros Frota também 


\section{H'INTERACÃO EM PSICOLOGIA}

teve que interromper suas atividades durante esse período, já que os alunos dependiam da supervisão dos professores. Nos prontuários analisados foi visto que após esse ocorrido não foi possível dar continuidade ao atendimento de alguns pacientes, seja por não se conseguir contato através do número telefônico deixado, seja pela perda de interesse do paciente devido à demora ou pelo fato de já estarem sendo atendidos em outros lugares.

Ainda como um fator inerente à própria conformação do serviço, em alguns casos o paciente deixou claro o incômodo pela troca de estagiários. Mesmo que não tenha nenhum registro explícito de abandono por esse fator, sabemos que a troca, que é própria do movimento de mudanças de turmas do curso, pode ter efeitos sob os tratamentos: "Disse que tinha mais intimidade com a estagiária que atendia anteriormente" (P211), ou no caso do P81, onde a mãe da criança só queria que o filho voltasse para o atendimento quando fosse com uma estagiária que pudesse lhe atender por mais tempo.

Em relação aos estagiários, gostaríamos de abrir uma discussão importante, já que foram eles que estiveram à frente de todo o atendimento, fazendo, inclusive, os registros nos prontuários. A intertextualidade, propriedade que têm os textos de serem cheios de outros textos, foi muito encontrada nos prontuários analisados. Por se tratar de um documento do paciente sob a responsabilidade do estagiário, já supomos que apareceriam ao menos duas vozes marcantes. 0 estagiário aparece nos registros e o paciente tem muitas de suas falas transcritas por se configurarem informações importantes para o acompanhamento do caso. No entanto a outra voz que apareceu de forma acentuada foi a da equipe dos profissionais da saúde, sobretudo do médico generalista e do psiquiatra. Os pacientes legitimavam a voz da equipe, colocando-se muitas vezes de uma maneira muito passiva em relação ao seu caso, em uma dependência não só com a equipe como com a medicação. Mais adiante apresentaremos como essas situações apareceram. Já os estagiários a legitimavam quando repetiam a queixa registrada no encaminhamento, inclusive através da mesma forma de "diagnosticar": "T.O.C." (P226), "Transtorno do Pânico" (P531), "Síndrome do Pânico" (P537).

De todos os motivos que podem influenciar na aderência ou não do tratamento, o fator número telefônico foi o que mais chamou nossa atenção. Dada a particularidade do serviço e de sua autonomia administrativa, o único meio de contactar com os pacientes se dá pelo número telefônico informado na ficha de triagem. Apesar do SPA dispor dos endereços dos pacientes, não faz parte da lógica do serviço entrar em contato por esse meio. Boa parte dos números telefônicos eram de celulares. 0 estagiário, ao tentar se comunicar com o paciente, não conseguia porque a ligação não completava a chamada, acusava número inexistente ou a linha telefônica tinha novo dono. Atrelado a esse fator, havia a questão do tempo decorrido entre a triagem e o primeiro contato para se iniciar os atendimentos. O SPA, por causa da grande procura por atendimentos, tem fila de espera. Esse dado demonstra a referência que hoje ele representa no município para casos de atendimento em psicologia. No entanto, devido à grande procura, há demora no início de alguns atendimentos. 0 primeiro contato com os pacientes após a triagem, algumas vezes, só ocorre depois de dois anos, quando muitos afirmam não terem mais interesse.

Ainda existiam as situações, como as das crianças, em que a demanda era da família ou da escola, que resultavam em uma não continuidade no atendimento porque a criança se recusava a ir ou porque o estagiário não identificava motivos para dar continuidade. De igual forma havia pacientes que só iam ao serviço pela imposição da equipe do Centro de Saúde da Família (CSF) "Médico e enfermeiro obrigaram ela a vir, sem isso não continuaria sendo atendida" (P231), "Tem transtorno de pânico e veio para o acompanhamento com o objetivo de retirar o remédio, a pedido do psiquiatra." (P298). Em ambos os casos os pacientes só foram para a triagem. 0 poderio do discurso biomédico tem sua força potencializada porque não é apenas o discurso do médico. Os pacientes também o internalizam e o consideram como o saber único, válido e verdadeiro. Em um dos prontuários analisados, P707, o paciente informou que não sabia se voltaria, pois tinha vindo ao SPA por encaminhamento do psiquiatra e que este tinha Ihe dado um prazo de atendimentos psicológicos e que ele (paciente) já tinha feito a parte dele vindo ao serviço. Aqui percebemos ocorrer uma interdiscursividade (união de vários discursos), na medida que o discurso do médico passa a ser o do paciente também. Ele não só o internaliza, como o reproduz. A interdiscursividade, na ADC, mostra como discursos particulares associam-se a campos sociais, interesses e projetos particulares, podendo ser associado a uma determinada prática. No caso citado vemos uma prática de legitimação do discurso do médico por parte do paciente.

Em menor escala, apareceram como motivos para abandono os seguintes casos: mudança de cidade, paciente sendo atendido em outro lugar, óbito e receio de vir ao serviço por considerá-lo "coisa de doido" (P263). Ainda tiveram os diversos casos em que o abandono carecia de explicação. Desistentes eram todos aqueles que comunicavam que não mais iriam, seja qual fosse o motivo. Houve ainda por parte de alguns a expectativa de que o estagiário pudesse ter condutas diferentes, como no caso P972, onde na última sessão o paciente demonstrou insatisfação ao não obter resposta quanto ao conselho pedido. Segundo registro do estagiário: "falou que não estava gostando de não receber as respostas que pedia, igualmente como o padre fazia quando o procurava para se confessar" (P972). Depois disso não mais voltou. Nesse mesmo sentido, no caso P924 a paciente solici- 


\section{4.' INTERACÃO EM PSICOLOGIA}

tou à estagiária um serviço de aconselhamento. Ao obter a resposta negativa falou que iria buscar atendimento com a sua antiga psicóloga que lhe aconselhava. Também nesse ponto, no P443 havia o registro que em uma das sessões o paciente relatou que estava com vontade de desistir por não encontrar respostas para seu problema e, ainda, no P693: "[...] menina falou que era a última vez que viria, pois sua mãe não estava gostando do trabalho aqui. A mãe queria que aqui passassem remédio e fizessem exames (eletrocefalograma)". Vemos, portanto, mais uma vez a interdiscursividade aparecendo de diversas formas, seja na reprodução da visão social do psicólogo como alguém que aconselha, seja manifestando um entendimento de terceiros.

0 atendimento psicológico não se configura como uma consulta com um médico. Ali o ato de falar, de poder dizer sobre tudo, pode deixar as pessoas surpresas. 0 abandono, em alguns casos, pode simbolizar a resistência, quando o paciente não desejar mais saber sobre si, sobre seu lugar no sintoma e justifica que não está em condições de continuar. Grande parte dos estagiários não cede às demandas de aconselhamento e aos pedidos por orientações, além de não ser o SPA um espaço em que atuam médicos, que prescrevem receitas de fármacos. A referência à medicação apareceu em 48,2\% dos casos. Uma vez que vêm encaminhados da APS e diante da dificuldade de atendimento psicológico nesse nível de atenção, passar a medicação tem se configurado como uma medida emergencial, a única solução tomada, em conjunto com o encaminhamento, diante dos casos de sofrimento psíquico. Em um estudo sobre consumo de benzodiazepínicos e antidepressivos por mulheres no município de Sobral, Gomes (2015) constatou que o uso da medicação tem a média temporal de pelo menos cinco anos, sendo o principal prescritor o médico do CSF. Os pacientes traziam uma naturalização do uso da medicação, como no P838, no qual o paciente afirma que procurou o SPA para complementar o uso da medicação, e do P701, que afırmou que não consegue viver sem a medicação. Há uma aceitação da dependência ao remédio como no $\mathrm{P} 423$, que "queria muito um remédio que aliviasse as crises por ele vivenciadas", no P531, que "está se sentindo bem melhor que os remédios estão fazendo efeito", no P460: "mostrou-se dependente de cada comprimido ingerido diariamente", e o P537: "Fala que foi dependente de remédios para os nervos, mas conseguiu se livrar. Mas anda com o bolso cheio de remédios. Apesar de não tomar, se sente mais segura".

A presunção é um aspecto importante de se levar em consideração ao se utilizar a ADC. Para Fairclough (2003) ela é uma forma de consenso, normalização e aceitação, proposição tomada por quem a manifesta como já dada. O que temos, portanto, é uma lógica assim construída: o discurso biomédico bombardeia com a informação que só a medicação resolve, ele é o discurso da ciência e a ciência está do lado que diz a verdade. Logo tomar medicação é o mais adequado a se fazer porque é o mais rápido e o mais eficiente. Isso é o que Fairclough (2003) nomeia como economia baseada no conhecimento: "[...] uma economia em que o conhecimento e a informação adquirem um novo e decisivo significado, implica uma economia baseada no discurso: o conhecimento se produz, circula e é consumido como discursos" (p. 188).

Entretanto, também conseguimos perceber tensionamentos e mesmo resistências a respeito desse discurso. Alguns pacientes trouxeram os contratempos do uso da medicação e a vontade de se livrar do remédio: "Não toma medicação porque não quer ficar dependente de remédio" (P510), "Conta que está muito sonolento por conta dos remédios, tendo problemas para conciliar sono e trabalho" (P226), "Pretende fazer psicoterapia, pois não quer ficar dependendo só de remédio" (P599) e "O clínico geral receitou fluoxetina, mas ele acha que o acompanhamento psicológico é mais válido do que a medicação." (P809). Há ainda os casos em que essa relação se revela ambivalente. Alguns dizem quererem se livrar, mas não abrem mão daquilo que consideram precioso.

Por isso não podemos ter a compreensão simplista de que o atendimento individual é o único fator responsável pelo abandono ou malogro do tratamento. Nossa pesquisa nos indica que as questões subjetivas, os efeitos e as resistências que surgem durante o processo psicológico não são possíveis de se medir pela duração ou continuidade do atendimento. Cunha e Benetti (2009) consideram que pesquisar sobre a efetividade de uma terapia tomando como base apenas os casos que chegaram ao término é no mínimo limitado. Até mesmo a compreensão da conclusão do tratamento é um entendimento extremamente delicado e complexo, se observarmos com atenção as variáveis que intervêm no processo terapêutico.

Por fim, existem casos em que o abandono do processo se deu por uma decisão do próprio paciente diante de uma percepção subjetiva de melhora, como no caso do P411, em que a paciente afirmou que estava se sentindo muito bem e por essa razão estava se desligando, e do P129, que considerava que não precisava mais do atendimento individual, pois queria dar um tempo para ver se estava bem, "queria caminhar com as próprias pernas". Já no caso do P740 a paciente, que já havia passado pelo serviço, retornou porque considerava que com os atendimentos tinha ficado melhor; no do P649, o paciente relatou que desde o início do atendimento não tomava mais medicação, já que estava se sentindo muito bem.

Ampliando um pouco mais o campo de discussão, também é importante que situemos a desistência como também recorrente de uma dificuldade do estagiário em manejar os atendimentos. 0 aluno diante da vivência do estágio pode se deparar com situações que mobilizam a sua própria resistência, dificultando o prosseguimento do tratamento. Por 


\section{MLE INTERACÃO EM PSICOLOGIA}

isso é necessário que o estagiário também invista em uma análise ou tratamento psicoterápico de apoio. Acerca desse ponto de discussão, concordamos com Mantovani, Marturano \& Silvares (2010), quando ampliam os motivos do abandono como sendo da ordem das variáveis clínicas, institucionais e da própria relação terapêutica. Soma-se a isso um aspecto importante de ser levado em consideração diante das características do período de modernidade tardia em que vivemos, marcado pelas novas formas de vigilância, autocontrole do estilo de vida e monitoramento constante do indivíduo (Luiz \& Cohn, 2006). Podemos acrescentar ainda como características deste tempo as relações fluidas e descartáveis, o imediatismo. Queremos que tudo ocorra da forma mais rápida, afınal não temos tempo a perder nesse mundo globalizado de tanta informação e possibilidades. Os produtos se tornam ultrapassados da noite para o dia, na espreita sempre há mais um lançamento pronto a ser consumido. Não fugindo da regra, os relacionamentos se tornam frágeis. Como um objeto de consumo, a pessoa pode ser trocada, substituída ou descartada, se perder sua utilidade.

0 poderio do discurso biomédico também tem sua força potencializada, uma vez que se trata de um modelo reproduzido em cada pequena ação do dia a dia. Se vamos ao psicólogo, muitas vezes solicitamos uma medicação para aliviar a dor que nos atormenta. E não adianta explicar que psicólogo não passa remédio, então é porque esse doutor não presta! Os usuários também estão muito bem adequados a esse modelo de medicalização dos sintomas e um dos motivos do abandono do tratamento também pode estar relacionado à ausência de prescrição de medicamentos e da frustração da expectativa de alívio imediato do sofrimento subjetivo e da angústia. Para Doescher e Henriques (2012) "Na sociedade do fast-food a angústia tem de ser banida, a dor negada, o sofrimento afastado, os sonhos enterrados." (p. 119).

Convém ainda que pensemos sobre a crítica, presente nos estudos sobre abandono, ao que nomearam como a limitação da atuação clínica. 0 entendimento sobre o conceito de clínica apareceu sob uma forma reduzida e com confusão da atuação com o espaço físico, tendo apenas dois artigos com uma discussão ampliada do que esta seja. Para Ferreira Neto \& Penna (2006), se no passado houve uma grande ênfase na clínica, hoje se percebe uma negligência desta nas formações em Psicologia, subestimando seu impacto na formação geral do aluno. Afırmam que falta ainda dentro dos cursos dialogar mais com as habilidades clínicas que têm seus efeitos para além de quatro paredes. Souza, Barros Neta \& Vieira (2012) desmistificam esse entendimento da clínica como um espaço restrito ao consultório. Segundo eles, fazer clínica não é simplesmente definir uma área de atuação, mas uma forma de se posicionar.
Por fim, consideramos que os motivos que fazem os pacientes ficarem ou partirem são diversos e singulares. 0 certo é que os efeitos dos atendimentos são imprevisíveis e que não podemos medir a amplitude de seus impactos e alcances. 0 que se constata é o encontro com um lugar de abertura para a escuta, que pode ser retomado após uma eventual interrupção. Isso é o que nos mostra os dezessete casos que foram reincidentes: os pacientes voltaram a procurar o serviço por demanda espontânea depois de um período de descontinuidade dos atendimentos.

\section{CONSIDERAÇÕES FINAIS}

Como um desdobramento da pesquisa, por mais que não possamos explorar tal dado, devemos pontuar aqui o tempo médio de duração do atendimento. Um mês foi o tempo médio de tratamento que mais prevaleceu. No entanto, o fato evidenciou outras variáveis, como falta de transporte público e o fato do SPA funcionar apenas em horário comercial, ou seja, muito mais do âmbito das problemáticas sociais do que do desejo dos pacientes em dar continuidade aos atendimentos.

Cabe também mencionarmos como aspecto fundamental de nossa pesquisa o fato de que, em se tratando de atendimento psicológico, há uma diferença muito grande entre conveniência e resistência. Como apresentado ao longo do texto, o abandono de um processo de acompanhamento psicológico pode ter muito mais relação com questões individuais do sujeito, com o não desejar mais saber sobre si, sobre seu lugar no sintoma decorrendo, muitas vezes, de interpretar que não está em condições de continuar o processo, por isso o abandono.

O uso da Análise de Discurso Crítica (ADC) nos fez colocar em cena discursos que também atravessam o fenômeno estudado. A expectativa dos pacientes em relação a um tratamento que estivesse em conformidade com o modelo biomédico e farmacológico foi um fator importante a ser considerado na avaliação das interrupções do tratamento. Tais observações feitas servem de argumentos para ampliar a discussão com os autores do campo, que justificavam a ineficácia da clínica através do que consideram grandes taxas de abandono.

As clínicas-escola são locais onde muitas atividades podem ser desenvolvidas, mas é sobretudo da atividade de escuta clínica que esse local trata. Os sujeitos e seus sofrimentos, no âmbito da assistência à saúde, vêm de um histórico de encaminhamentos, silenciamentos e deslocamentos. São exatamente os serviços-escola de psicologia que sobrevivem e resistem no trabalho de escuta e acolhida dessas dores. A clínica não morreu e as filas de espera e as grandes demandas são a prova disso. 


\section{WINTERAÇO EM PSICOLOGIA}

Não queremos, contudo, questionar a importância de técnicas diversas, de trabalhos diferenciados e complementares tais como atividades grupais, orientação profissional, plantão psicológio, etc. As atividades terapêuticas em grupo têm seu valor e são importantes, mas não podem ser a única forma de se lidar com os sofrimentos, com aquilo que não tem lugar ou que apenas uma medicação não dá conta. Embora não necessite ser o único meio de atendimento em tais espaços, o atendimento individual não pode ser, em hipótese alguma, suprimido.

Finalmente, salientamos que nossa pesquisa teve como foco apenas os atendimentos encaminhados da Atenção Primária à Saúde. É importante que se diga que a forma de acesso mais recorrente ao SPA é a demanda espontânea. 0 encaminhamento por si só tem seus entraves. É provável que, se focássemos nos casos que chegaram por demanda espontânea, poderíamos deparar-nos com um cenário diferente em relação à situação de abandono.

\section{DECLARAÇÃO DE FINANCIMENTO}

A pesquisa relatada no manuscrito foi financiada parcialmente pela bolsa de mestrado da primeira autora (CAPES).

\section{REFERÊNCIAS}

Ancona-Lopes, M. (1983). Considerações sobre o atendimento fornecido por clínicas-escola de psicologia. Arquivos Brasileiros de Psicologia, 2,(35), 123-135. Repositório FGV de Periódicos e Revistas. http://bibliotecadigital.fgv.br/ ojs/index.php/abp/article/view/18922/17664

Bados, A., Balaguer, G., \& Saldaña, C. (2007). The efficacy of cognitive-behavioral therapy and the problem of drop-out. Journal of Clinical Psychology, 63(6), 585-592. https://doi. org/10.1002/jclp.20368

Campezatto P. V. M., \& Nunes, M. L. T. (2007). Atendimento em clínicas-escola de psicologia da região metropolitana de Porto Alegre. Estudos de Psicologia, 24(3), 363-374. https://doi.org/10.1590/S0103-166X2007000300008

Cunha, T. R. S., \& Benetti, S. P. C. (2009). Caracterização da clientela infantil numa clínica-escola de psicologia. Boletim de Psicologia, 59(130), 117-127. Periódicos em Psicologia. http://pepsic.bvsalud.org/scielo.php?script=sci_ arttext\&pid=S0006-59432009000100010\&Ing=pt\&tIng=pt.

Doescher, A. M. L., \& Henriques, W. M. (2012). Plantão psicológico: um encontro com o outro na urgência. Psicologia em Estudo, 17 (4), 717-723. https://doi.org/10.1590/S141373722012000400018

Fairclough, N. (2001). Discurso e mudança social.(1 ${ }^{\mathrm{a} e d .}$.) Editora Universidade de Brasília.
Fairclough, N. (2003). El análisis crítico dei discurso como método para la investigación em ciências sociales. In $\mathrm{R}$. Wodak, \& M. Meyer (Org.), Métodos de análisis critico dei discurso. (1a ed.) (pp. 179-294). Gcdisa.

Ferreira Neto, J. L., \& Penna, L. M. D. (2006). Ética, clínica e diretrizes: a formação do psicólogo em tempos de avaliação de cursos. Psicologia em Estudo, 11(2), 381-390. https:// doi.org/10.1590/S1413-73722006000200017

Gauy, F. V., \& Fernandes, L. F. B. (2008). Um panorama do cenário brasileiro sobre atendimento psicológico em clínicas-escola. Paidéia, 18(40), 401-404. https://doi. org/10.1590/S0103-863X2008000200016

Giddens, A. (1991). As consequências da modernidade. (2a ed.). UNESP.

Jung, S. I., Serralta, F. B., Nunes, M. L. T., \& Eizirik, C. L. (2014). Momentos distintos no abandono da psicoterapia psicanalítica. Jornal Brasileiro de Psiquiatria, 63(2), 133-141. https://doi.org/10.1590/0047-2085000000017

Justen, A., Paltanin, E. S., Maroneze, G. S., Vissovatz, M. M., Prá, J. D., Feltrin, J., Silva, M. A., Mariussi, M. C., Pereira, R. S., \& Lima, O. M. P. (2010). Identificação da população atendida no Centro de Psicologia aplicada da Universidade Paranaense. Arquivos de Ciência da Saúde da UNIPAR, 14(3), 197-209. https://doi.org10.25110/arqsaude. v14i3.2010.3661

Lhullier, A., Nunes, M. L., \& Horta, B. (2006). Preditores de abandono de psicoterapia em pacientes de clínica-escola. In: Silvares, E. F. M. (Org.), Atendimento psicológico em clínicas-escola (pp. 229-256). Alínea.

Luiz, O. C., \& Cohn, A. (2006). Sociedade de risco e risco epidemiológico. Cadernos de Saúde Pública, 22(11), 2339-2348. https://doi.org/10.1590/S0102-311X2006001100008.

Mantovani, C. C. P., Marturano, E. M., \& Silvares, E. F. M. (2010). Abandono do atendimento em uma clínica-escola de psicologia infantil: variáveis associadas. Psicologia em estudo, 15(3), 527-535. https://doi.org/10.1590/S141373722010000300010.

Maravieski, S., \& Serralta, F. B. (2011). Características clínicas e sociodemográficas da clientela atendida em uma clínica-escola de psicologia. Temas em Psicologia, 19(2), 481-490. Periódicos Eletrônicos em Psicologia. https:// pepsic.bvsalud.org/scielo.php?script=sci_arttext\&pi$\mathrm{d}=$ S1413-389X2011000200011\&lng=pt\&tlng=pt.

Prebianchi, H. (2011). Atenção psicológica infantil: compreensão de usuários e estagiários do serviço-escola. Psicologia em Revista, 17(2), 322-339. Periódicos em Psicologia. https://pepsic.bvsalud.org/scielo.php?script=sci_arttext\&pid=S1677-11682011000200011\&lng=pt\&tlng=pt.

Prebianchi, H., \& Cury, V. (2005). Atendimento infantil numa clínica-escola de Psicologia: Percepção dos profissionais envolvidos. Paidéia, 15(31), 249-258. https://doi. org/10.1590/S0103-863X2005000200012. 
Resende, V., \& Ramalho, V. (2011). Análise de discurso (para a) crítica: 0 texto como material de pesquisa. ( $2^{\mathrm{a}}$ ed.)Ponte Editores.

Sassi, R., \& Maggi. A. (2007). Demandas de Psicologia escolar para uma clínica-escola. Psico), 38(1), 35-44. Revistas Eletrônicas da Pontifícia Universidade Católica do Rio Grande do Sul. https://revistaseletronicas.pucrs.br/revistapsico/ ojs/index.php/revistapsico/article/view/1922/1428
Sei M. B., \& Colavin, J. R. P. (2016). Desistência e abandono da psicoterapia em um serviço-escola de Psicologia. Revista Brasileira de Psicoterapia, 18(2), 37-49. Centro de Estudos Luís Guedes. https://rbp.celg.org.br/detalhe_artigo. asp?id=200

Souza, E. L. C., Barros Neta, F. T., \& Vieira, E. M. (2012). Interface do plantão psicológico e as políticas de assistência social. Revista do NUFEN, 4(2), 71-82. Periódicos em Psicologia. http://pepsic.bvsalud.org/scielo.php?script=sci_ arttext\&pid=S2175-25912012000200008\&lng=pt\&tlng=pt.

Submetido em: 18/07/2019 Primeira decisão editorial em: 22/03/2020 Aceito em: 09/04/2020 